\title{
Nitrazepam for Periodic Movements in Sleep (Sleep-related Myoclonus)
}

\author{
Harvey Moldofsky, Carole Tullis, Grace Quance and Franklin A. Lue
}

\begin{abstract}
In a follow-up study (mean, approximately six months), nitrazepam was helpful in suppressing periodic movements in sleep (sleep-related myoclonus) and improving disturbed sleep physiology and daytime symptoms of 13 patients (mean age $-53 \mathrm{yr}$ ).
\end{abstract}

RÉSUMÉ: Le nitrazepam dans les mouvements périodiques pendant le sommeil (myoclonies du sommeil) Nous démontrons, à la suite d'une étude suivie pour au moins 6 mois, que le nitrazepam est utile pour supprimer les mouvements périodiques observés pendant le sommeil (myoclonies du sommeil) et pour améliorer la physiologie troublé du sommeil et les symptômes diurnes chez 13 patients (âge moyen 53 ans).

Can. J. Neurol. Sci. 1986; 13:52-54

Sleep-related (nocturnal) myoclonus or periodic movements in sleep (PMS) are periodic, involuntary, stereotyped movements of the lower limbs that typically occur at 20- to 40 -sec intervals during sleep. ${ }^{2}$ PMS has been found in $13.3 \%$ of disorders of initiating and maintaining sleep (insomnia) and $6.9 \%$ of disorders of excessive daytime somnolence among 6,422 patients investigated by polysomnography. ${ }^{2}$ The disorder is found in $18 \%$ of the aged $;^{2}$ accompanies certain medical disorders including end stage renal disease ${ }^{3}$ rheumatic pain modulation disorder or "fibrositis syndrome" , 4 and restless legs syndrome ${ }^{4}$ and may be associated with sleep-related disorders, narcolepsy and cataplexy; ${ }^{5}$ and sleep apnea. ${ }^{2}$ The etiology of this disorder is unknown. Anecdotal reports have suggested varyingly successful treatment with folic acid, ${ }^{6}$ iron supplement, ${ }^{7}$ an alpha-receptor blocking agent, ${ }^{8}$ and several benzodiazepine medications, e.g., lorazepam, ${ }^{9}$ temazepam, ${ }^{10}$ and several with clonazepam. ${ }^{3}$ Symptomatic effects on those patients with daytime somnolence or insomnia and follow-up studies have not been systematically reported with any of these drugs.

In this paper we report on the efficacy of nitrazepam in controlling PMS and sleep-related and daytime symptoms in patients with either chronic insomnia or excessive daytime somnolence. Nitrazepam was selected because it is a benzodiazepine, structurally similar to clonazepam, ${ }^{16}$ has an elimination half-life somewhat shorter ( 15 to $38 \mathrm{hr}$ ) than clonazepam ( 18 to $50 \mathrm{hr}$ ), and, like clonazepam, has been shown to be effective in the treatment of myoclonic epilepsy. ${ }^{12}$

\section{Materials AND Method}

Thirteen patients who had been investigated with medical and psychiatric examinations for complaints of excessive daytime somnolence (EDS, $\mathrm{N}=8$ ) or intractable disorder of initiating and maintaining sleep (DIMS, $N=5$ ) were found by polysomnography to have PMS. The patients (10 males, 3 females, mean age $53.3 \mathrm{yr}$ ) had their disorders for a mean of 7.3 years (S.D., 9.8). None of the patients had any other sleeprelated disorder. Within the group, there were a variety of medical disorders: two had essential hypertension; one had a residual mild left-sided stroke; one had partial complex epilepsy controlled by phenytoin; one had leg cramps; three had end stage renal disease successfully treated by continuous ambulatory peritoneal dialysis; two had restless legs syndrome with migraine and "fibrositis syndrome"; one had iron deficiency anemia associated with menorrhagia treated by ferrous sulphate; one had coronary artery disease, chronic low back and lower limb pain; and one had no associated medical or psychiatric disorder. They had not received any hypnotic, tranquilizer or antidepressant medication for at least two weeks prior to the initial, or baseline, sleep study. If indicated, they continued with their antihypertensive, cardiac, or antacid medications.

Sleep studies were carried out in a sound-attenuated bedroom over one night. During the previous day, neither alcohol, caffeine substances, nor naps were permitted. Sleep recordings consisted of electroencephalogram (EEG) C3-A2 and C4-A1,

From the Sieep Disorders Clinic, Department of Psychiatry, Toronto Western Hospital, Toronto

Received May 30, 1985. Accepted in revised form November 21, 1985

Reprint requests to: Harvey Moldofsky, M.D., Department of Psychiatry, Toronto Western Hospital, 399 Bathurst Street, Toronto, Ontario, Canada MST 2S8 
electro-oculogram (EOG), submental electromyogram (EMG) and electrocardiogram (EKG). Surface EMG recordings were obtained from the lower limbs over anterior tibialis muscles.

Sleep recordings were scored in 40-sec epochs according to standard criteria. ${ }^{13}$ Leg activity was tabulated separately for each limb: leg jerks were counted when anterior tibialis EMGs showed activity bursts of 0.5 to $4.0 \mathrm{sec}$ in duration with a periodicity ranging between 5 and $120 \mathrm{sec}$ and following the criteria suggested in the Diagnostic Classification of Sleep and Arousal Disorders.' To adjust for variable total sleep time for each subject the mean number of EMG bursts of activity per hour of sleep was calculated for each leg, and the leg with the higher number was used for comparison. Also calculated as means per hour of sleep were: number of movement arousals, number of wakes after sleep onset, and number of sleep stage changes. Percent time was calculated for wakefulness after sleep onset, stages 1, 2, 3, 4, Non Rapid Eye Movement (NREM) sleep and Rapid Eye Movement (REM) sleep.

Self ratings immediately before and after sleep were made of pain and stiffness in 10 specific body regions, on a scale of 0-6 in severity and totalled from all regions (scale of $0-60$ severity). ${ }^{14}$ Sleepiness was assessed on a scale of 0-6 in severity using the Stanford Sleepiness Scale. ${ }^{15}$ Physical fatigue was similarly rated on a scale of 0 (none) to 6 (totally exhausted). ${ }^{4}$

The patients were prescribed nitrazepam $5 \mathrm{mgm}$ tablets 45 min before bedtime, and were advised to avoid all alcoholic and caffeine-containing beverages. They were followed on an outpatient basis for initial adjustment of their medication upwards to a maximum of $10 \mathrm{mgm}$ or downwards to a minimum of $2.5 \mathrm{mgm}$. They were maintained at a constant individualized dose to provide optimal symptomatic relief and minimize any untoward effects. A night of polysomnography was performed at a mean of 6.6 months (S.D., 4.9) in the same way as in the baseline study.

The effects of nitrazepam on fatigue, sleepiness, pain and sleep physiologic measures for all patients were determined by comparing baseline to follow-up values using two-tailed $t$-tests. Follow-up assessment including a global self-rating of sleep quality and daytime symptoms (scale of 0 , no change or worse, to 4 , excellent) was performed independently by a single observer in a subsequent interview.

\section{RESULTS}

After approximately six months of treatment with nitrazepam all 13 patients showed reduced leg jerks during sleep, increased percentage of stage 2 sleep and sleep efficiency (proportion of time asleep to time in bed) (see Table 1). Nitrazepam was also effective in improving sleep disturbance as indicated by a reduction in movement arousals, sleep stage changes and awakenings from sleep. Further, nitrazepam reduced the percent of wakefulness after sleep onset and tended to increase the duration of sleep (see Table 1).

There was no overnight difference in self ratings of moderate fatigue and sleepiness in the 5 patients complaining of insomnia, and the 8 patients complaining of daytime sleepiness. The latter group required less medication (mean dose $2.8 \mathrm{mgm}$ ) than those in the insomnia group (mean dose $7.8 \mathrm{mgm}, \mathrm{p}<.02$ ). At follow-up, the patients continued to describe moderate fatigue and sleepiness before and after polysomnography. However, in the independent clinical assessment they rated themselves as globally
Table 1: Sleep measures at baseline versus treatment with nitrazepam

\begin{tabular}{|c|c|c|c|c|}
\hline \multicolumn{5}{|c|}{ All Patients $(n=13)$} \\
\hline & \multicolumn{2}{|c|}{ BASELINE } & \multicolumn{2}{|c|}{ TREATMENT } \\
\hline & Mean & s.d. & Mean & s.d. \\
\hline Total Sleep Time (Hr) & 5.16 & 1.63 & $6.33^{b}$ & 1.17 \\
\hline Latency to Stage 2 onset (min) & 21.99 & 10.93 & 24.72 & 18.58 \\
\hline Latency to REM onset (min) & 112.15 & 66.64 & 107.40 & 55.70 \\
\hline$\%$ Stage 1 & 7.89 & 5.50 & 5.56 & 2.38 \\
\hline$\%$ Stage 2 & 39.62 & 11.92 & $58.50^{\mathrm{d}}$ & 8.95 \\
\hline$\%$ Stage 3 & 6.48 & 4.00 & 8.88 & 5.68 \\
\hline$\%$ Stage 4 & 6.15 & 7.30 & $2.91^{\mathrm{a}}$ & 4.49 \\
\hline$\%$ REM & 13.26 & 5.76 & 14.96 & 5.30 \\
\hline Sleep Efficiency (\%) & 71.78 & 17.08 & $86.81^{b}$ & 10.60 \\
\hline \multicolumn{5}{|l|}{$\%$ Stage Wake } \\
\hline after sleep onset & 26.11 & 17.92 & $8.72^{c}$ & 7.51 \\
\hline Movement arousals* & 10.29 & 5.37 & $5.46^{\mathrm{c}}$ & 3.18 \\
\hline Sleep stage changes* & 12.22 & 4.27 & $8.10^{c}$ & 2.26 \\
\hline Wakenings* & 2.78 & 2.12 & $1.28^{\mathrm{b}}$ & 0.76 \\
\hline \multicolumn{5}{|l|}{ Higher no. of leg } \\
\hline EMG bursts* & 59.43 & 41.75 & $21.07^{\mathrm{c}}$ & 16.96 \\
\hline
\end{tabular}

* number per hour of sleep

a $.05<\mathrm{p}<.10$

${ }^{b} \mathrm{p}<.05$

$c \mathrm{p}<.01$

${ }_{\mathrm{p}}^{\mathrm{p}}<.002$

having excellent overall improvement in sleep quality and daytime symptoms, mean 3.4 (S.D., 0.8). Furthermore, the 2 patients with fibrositis syndrome and the 3 patients with end stage renal disease experienced improvement in musculoskeletal pain $(p<.05)$. Only one patient experienced untoward effects with the drug. She complained of some sluggishness and impaired daytime concentration. After five months she stopped the nitrazepam and her nocturnal restlessness and insomnia recurred.

\section{Discussion}

Nitrazepam has been shown to be helpful in reducing nocturnal leg jerks and improving the sleep physiology of patients with PMS. Pre-and post-sleep laboratory self-ratings of fatigue and sleepiness were unchanged, but the global self-ratings of sleep quality and daytime symptoms were very much improved. While the study does not include a placebo-control group, patients are usually unaware of the periodic movements during sleep' and this disorder is chronic, remains fairly stable, or is progressive with age. ${ }^{2}$ The coincident improvement in musculoskeletal pain, especially in the 2 patients with "fibrositis syndrome" and sleep-related myoclonus, is in accord with the previous studies of an association between an NREM EEG arousal disorder and musculoskeletal pain in such patients. ${ }^{4}$ All 3 patients with end stage renal disease treated by peritoneal dialysis who complained of severe insomnia, daytime exhaustion and widespread nonarticular musculoskeletal aching were remarkably improved, without change to the metabolic state associated with their disease. The moderate fatigue and sleepiness experienced upon awakening in the morning probably relate to the continued sedative effect of nitrazepam, but the symptoms dissipated early in the morning and did not prove troublesome except in one patient. This observation is consistent with the patients' global self-ratings and previous clinical reports of uncommon residual daytime sedative complaints. ${ }^{16}$ 
While nitrazepam does have a moderately prolonged elimination halflife and tends to accumulate in the plasma with regular dosing until a steady state is reached, there is no clear association between plasma concentration of the drug and daytime performance in young and elderly subjects. ${ }^{17}$

Because the disorder has been identified in a variety of medical and sleep-related disorders, PMS has been suggested to be a non-specific feature of fragmented or disordered sleep. ${ }^{18}$ The neuromotor mechanism that provokes the appearance of this disorder during sleep is unknown. The daytime symptoms may relate to the influence of involuntary leg jerks on sleep physiology. The fact that suppression of leg jerks and improvement in sleep efficiency by nitrazepam remedies daytime complaints implies a connection between the frequency of sleep-related limb movements and associated sleep fragmentation to daytime symptoms.

A double-blinded placebo-controlled study with cross-over would further clarify the specificity of this medication. The reason for the beneficial effect of nitrazepam and similar benzodiazepines for PMS-related disorders must await further elucidation of the possibility of the existence of multiple benzodiazepine receptors and certain classes of benzodiazepines having selective CNS receptor and behavioral effects. ${ }^{19}$ Information on the specific central nervous system functions affected by nitrazepam would contribute to knowledge of the etiology of this ubiquitous, troublesome, common sleep disorder.

\section{ACKNOWLEDGEMENTS}

We thank M. Gupta, M.D., for assistance, L. Laws for secretarial help, D.G. Oreopoulos, M.D., D.A.Gordon, M.D. and J. Reynolds, M.D. of the Department of Medicine of the Toronto Western Hospital for referring many of the patients.

The study was supported by the Medical Research Council of Canada Grant No. MA-7733.

\section{REFERENCES}

1. Diagnostic Classification of sleep and arousal disorders: Association of Sleep Disorders Centres and the Association for the Psycho-physiological Study of Sleep, Ist ed. Sleep 1979; 2.

2. Coleman RM, Bliwise DL, Sajben N et al. Epidemiology of periodic movements during sleep. In: Guilleminault $\mathrm{C}$ and Lugaresi $\mathrm{E}$, eds. Sleep-Wake Disorders: Natural History, Epidemiology, and Long Term Evolution. New York: Raven Press, 1983, pp 217-229.
3. Read DJ, Feest TG, Nassim MA. Clonazepam: effective treatment for restless legs syndrome in uremia. Br Med J (Clin Res) 1981; 3 : 283: 855-856.

4. Moldofsky H, Tullis MA, Lue FA et al. Sleep-related myoclonus in rheumatic pain modulation disorder (Fibrositis Syndrome) and in excessive daytime somnolence. Psychosom Med 1984; 46: 145-151.

5. Mosko SS, Shampain DS, Sassin JF. Nocturnal REM latency and sleep disturbance in narcolepsy. Sleep 1984; 7: 115-125.

6. Botez MI, Cadotte M, Beaulieu et al. Neurological disorders responsive to folic acid therapy. Can Med Assoc J 1976; 115: 217-223.

7. Norlander NB. Therapy in restless legs. Acta Med Scand 1953; 145 453-457.

8. Ware JC, Pittard JT, Blumoff RL. Treatment of sleep-related myoclonus with an alpha-receptor blocker. Sleep Res 1981; 10: 242.

9. Bellinghier G, Savica V, Mallamace A et al. Restless legs syndrome and therapeutic effect of lorazepam: preliminary report. (Abstract) Proc Eur Dial Transplant Assoc 1983; 10 (20th Congress).

10. Mitler M, Browman CP, Gujavarty K, Timms RM, Menn SJ. Nocturnal myoclonus treatment efficiency of clonazepam and temazepam. (Abstract) Sleep Res 1980; 9: 58.

11. Kangas L, Breimer DD. Clinical pharmacokinetics of nitrazepam. Clin Pharmacokinet 1981; 6: 346-366.

12. Bellantuona C, Reggi V, Tognoni G, Garattini S. Benzodiazepines: Clinical pharmacology and therapeutic use. Drugs 1980; 19: 195-219.

13. Rechtschaffen A, Kales A, eds. A manual of standardized terminology, techniques, and scoring system for sleep stages of human subjects. Washington: NIH Pub No 204, 1968.

14. Moldofsky H, Scarisbrick P, England R, Smythe H. Musculoskeletal symptoms and nonREM sleep disturbance in patients with "Fibrositis Syndrome" and healthy subjects. Psychosom Med 1975; 37: 341-351.

15. Hoddes E, Dement WC, Zarcone V. The development and use of the Stanford Sleepiness Scale (SSS). Psychophysiology 1972; 9: 150.

16. Greenblatt DJ, Allen MD. Toxicity of nitrazepam in the elderly: a report from the Boston Collaborative Drug Surveillance Program Br J Clin Pharmacol 1978; 5: 407-413.

17. Mattila MJ, Aranko K, Matilla ME, Stromberg C. Objective and subjective assessment of hangover during subacute administration of temazepam and nitrazepam to healthy subjects. Eur J Clin Pharmacol 1984: 26: 375-380.

18. Coleman RM, Pollak CP, Weitzman ED. Periodic movements in sleep (Nocturnal Myoclonus): Relation to sleep disorders. Ann Neurol 1980; 8: 416-421.

19. Martin TL, Brown CL, Doble A. Multiple benzodiazepine receptors: Structures in the brain or structures in the mind? A critical review. Life Sci 1983; 32: 1925-1933. 